\title{
Reaction time and visual area: Searching for the determinants
}

\author{
CLAUDE BONNET \\ Université René Descartes, Paris, France \\ and \\ JORGE GURLEKIAN and PAULA HARRIS \\ Laboratorio de Investigaciones Sensoriales, Buenos Aires, Argentina
}

\begin{abstract}
At constant luminance levels, simple reaction times (SRTs) decline when the size of luminous stimuli increases. Piéron's law fits such a decline. Combining the effect of size and luminance suggests that most of the decline of SRTs with increase in size can be attributed to a probability summation process.
\end{abstract}

Piéron's law (Piéron, 1920, 1952) describes a hyperbolic relation between simple reaction time (SRT) and intensity ${ }^{1}$ of a sensory stimulus. The most general formulation of the law is:

$$
\left(\mathrm{SRT}-t_{o}\right)=\beta I^{-\alpha},
$$

where SRT $=$ reaction time; $t_{o}=$ an asymptotic reaction time reached for the higher intensities, also called chronobasis; $I=$ the intensity of the stimulus; $\beta=$ a scale parameter; and $\alpha=$ is a sensory-specific parameter. On an empirical basis as well as on a theoretical one, several authors (e.g., Bonnet, 1990; Norwich, 1977, 1984; Norwich, Seburn, \& Axelrad, 1989; Restle, 1961) have assumed an identical exponent for Piéron's law, for Stevens's laws, and for the generalized Weber's law for the same stimuli.

The determinant(s) of SRTs to a lighted stimulus varying in area and luminance were investigated in the present study. In fact, the assumption of a "single psychophysical law," proposed by Norwich, may only be functionally valid if the three kinds of methods (SRT, discrimination, and magnitude estimation) assess an identical sensory dimension. In magnitude estimation and discrimination experiments, the stimulus dimension is defined to the subject via the intructions. In case of SRT measures, since the task is to assess the moment of appearance of a stimulus, the subject does not know a priori which will be the dimension of the stimulus that will generate the response.

The two following experiments were run to evaluate three assumptions about the possible cause of changes in SRTs with area. These experiments should provide insight into the factors that can modify SRT to visual stimuli varying in area and in luminance.

This experiment was run with the support of a convention between the CNRS (France) and the CONICET (Argentina). Acknowledgments are due to Lawrence Ward, who suggested the probability summation hypothesis. Correspondence should be addressed to $\mathrm{C}$. Bonnet, Laboratoire de Psychologie Expérimentale, Université René Descartes, EPHE, EHESS, Associé au CNRS, 28 Rue Serpente, Paris 75006, France.
Previous experiments by Piéron (1920), Mansfield (1973), and Ueno (1976) suggested that beyond the limits of areal summation (3-6 min of arc in photopic vision; e.g., Hood \& Finkelstein, 1986), the exponent of Piéron's function is approximately constant $(\alpha=-.33)$. Below that limit, the exponent increases. However, the chronobasis decreases when the size of the stimulus increases (e.g., Teichner \& Krebs, 1972). As we will demonstrate here, beyond the limits of spatial and temporal summation, SRTs still decline when the area of the stimulus increases.

One possible explanation of this effect attributes it to spatial frequency. When the spatial frequency of a sinewave grating increases, the SRTs increase, provided the spatial frequency is beyond some 1-3 cycles per degree (cpd) (Breitmeyer, 1984; Parker \& Salzen, 1977; Tolhurst, 1975). Increasing the area of a square figure decreases the fundamental spatial frequency of its amplitude spectrum. Since the spatial frequency component that contains the largest amount of energy is precisely its fundamental, it is possible that the change in SRTs with area

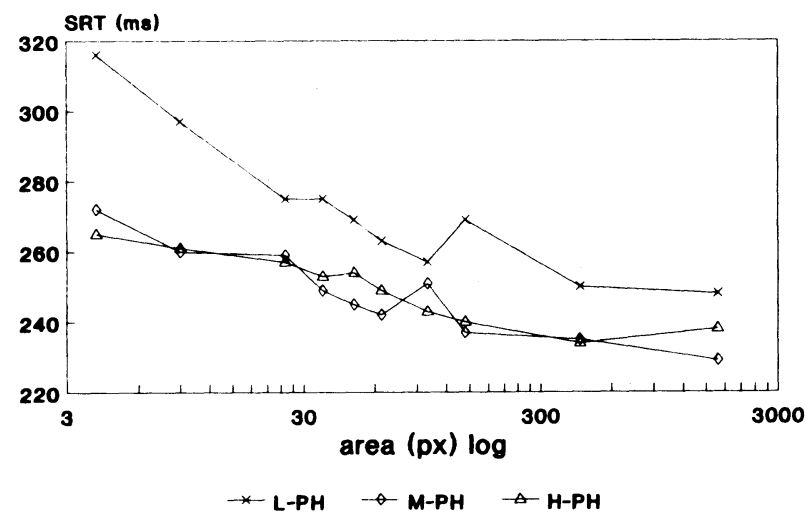

Figure 1. Individual simple reaction time (in milliseconds) as a function of area, with luminance as a parameter. Example taken from Experiment 2 (exposure time $=32 \mathrm{msec}$ ). Area is expressed in pixels. $L=0.78 \mathrm{~cd} / \mathrm{m}^{2}, M=9.93 \mathrm{~cd} / \mathrm{m}^{2}, H=73 \mathrm{~cd} / \mathrm{m}^{2}$. 
Table 1

Exponents, Chronobasis $\left(t_{0}\right)$ of Piéron's Law, and Confidence Coefincient for the Goodness of Fit as a Function of the Area of the Stimulus for Each Subject in the Two Experiments and for Each Level of Luminance

\begin{tabular}{|c|c|c|c|c|c|c|}
\hline \multirow[b]{2}{*}{ Subjects } & \multicolumn{3}{|c|}{ Experiment 1} & \multicolumn{3}{|c|}{ Experiment 2} \\
\hline & Exponent & $t_{o}$ & $r^{2}$ & Exponent & $t_{o}$ & $r^{2}$ \\
\hline \multicolumn{7}{|c|}{$I=0.78 \mathrm{~cd} / \mathrm{m}^{2}$} \\
\hline $\begin{array}{l}\text { N.R. } \\
\text { P.H. }\end{array}$ & $\begin{array}{l}-0.2748 \\
-0.7749\end{array}$ & $\begin{array}{l}216 \\
207\end{array}$ & $\begin{array}{l}.9329 \\
.9530\end{array}$ & $\begin{array}{l}-0.4170 \\
-0.4283\end{array}$ & $\begin{array}{l}225 \\
243\end{array}$ & $\begin{array}{l}.9405 \\
.9289\end{array}$ \\
\hline \multicolumn{7}{|c|}{$I=9.93 \mathrm{~cd} / \mathrm{m}^{2}$} \\
\hline $\begin{array}{l}\text { N.R. } \\
\text { P.H. }\end{array}$ & $\begin{array}{l}-0.2704 \\
-0.3206\end{array}$ & $\begin{array}{l}215 \\
207\end{array}$ & $\begin{array}{l}.9436 \\
.9275\end{array}$ & $\begin{array}{l}-0.0716 \\
-0.2713\end{array}$ & $\begin{array}{l}151 \\
219\end{array}$ & $\begin{array}{l}.6352 \\
.9138\end{array}$ \\
\hline \multicolumn{7}{|c|}{$I=73 \mathrm{~cd} / \mathrm{m}^{2}$} \\
\hline $\begin{array}{l}\text { N.R. } \\
\text { P.H. }\end{array}$ & $\begin{array}{l}-0.1117 \\
-0.1267\end{array}$ & $\begin{array}{l}175 \\
206\end{array}$ & $\begin{array}{l}.9650 \\
.8552\end{array}$ & $\begin{array}{l}-0.0392 \\
-0.0368\end{array}$ & $\begin{array}{l}100 \\
100\end{array}$ & $\begin{array}{l}.7380 \\
.8693\end{array}$ \\
\hline
\end{tabular}

would mostly result from the change in its fundamental frequency.

However, when using stimuli such as sine-wave gratings, the total energy (radiant or luminous flux) received by the retina remains constant at any spatial frequency. Now, if the stimulus is a light-square surface presented on a dark background, as in our experiment, the radiant flux will increase with the increase in area, even for a constant luminance level. Spatial summation holds essentially when the size of a visual stimuli is smaller than the mean size of the receptive fields of the ganglionar neurons. Beyond that limit, the number of activated neurons increases when the area of the luminous stimulus increases. The flux assumption would suggest a pooling effect of the neuronal activity generated by a given stimulus. It is then possible that, beyond the limits of temporal and spatial summations, the flux remains the determinant of SRT since it is very unlikely that SRT would depend only on local luminance of the stimulus.

There is still another possibility that might explain a decline in SRTs with the increase in area. The assumption is that the effects of luminance combine with the effect of area in a sort of probability summation effect.

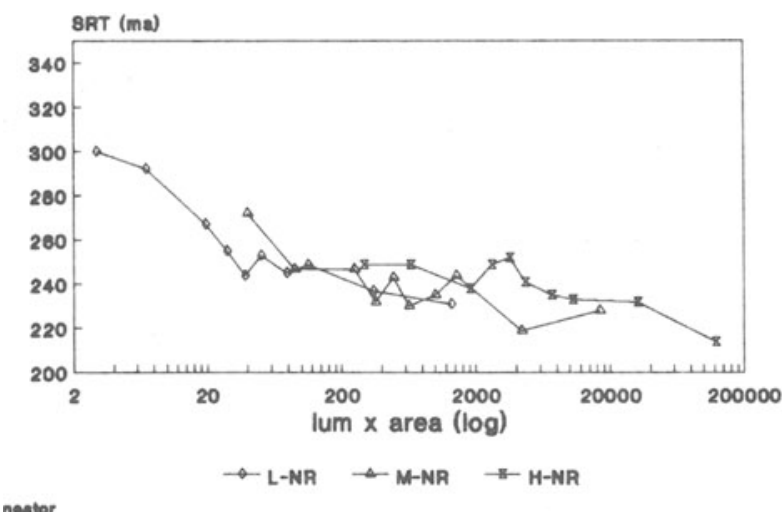

Any SRT model (e.g., Grice, 1968; Grice, Nullmeyer, \& Schnizlein, 1979; Link, 1992; Luce \& Green, 1972; McGill, 1963) assumes that the response is given when some kind of accumulation of information has reached a criterion level. This accumulation function can be conceived as stochastic, as it is in random walk models (e.g., Luce, 1986). Hence, the probability of reaching the response criterion at an earlier moment increases when the number of activated neurons increases. This is, in essence, the idea of probability summation (e.g., Colonius, 1990; Link, 1992).

The following two experiments were run to clarify the issues of the above assumptions.

\section{METHOD}

Stimuli were luminous squares shown on a monitor screen $(640 \times 400$ pixels) in a dimly illuminated room. They were generated with a VGA graphic card in a PC (80286). The subjects were placed at a distance of about $115 \mathrm{~cm}$, so that 1 pixel $=0.025^{\circ}$. Within a session, the area of the square varied randomly from trial to trial. Ten area sizes were used: $4,9,25,36,49,64,100,144,441$, and 1,681 pixels. These values corresponded to squares with sides of $3,4.5,7.5,9,10.5,12,15,18$, 31.5 , and $61.5 \mathrm{~min}$ of arc, respectively.

Three luminance levels of the squares were used in separate sessions: $0.78,9.93$, and $73 \mathrm{~cd} / \mathrm{m}^{2}$. The luminance of the screen was $0.04 \mathrm{~cd} / \mathrm{m}^{2}$.

In Experiment 1, the presentation of the stimulus was response terminated. As a consequence, exposure time equals RT. In Experiment 2, the presentation time was about $32 \mathrm{msec}(2$ frames). Measurements of RTs were realized on the basis of the internal clock of the computer to the closest millisecond.

The task of the subject was to press a response key as soon as the stimulus appeared. A $1000-\mathrm{Hz}$ sound $(500 \mathrm{msec})$ served as a preparatory signal. Five preparatory periods were used $(500,650,800,950$, and $1,100 \mathrm{msec}$ ) and were presented in a random order following an exponential distribution function in order to prevent anticipatory responses. Their frequencies were counterbalanced within a block of 20 trials. An experimental session contained 100 trials.

Two newly trained subjects took part in the two experiments. They went through three sessions for each level of luminance. Consequently, for every subject, for each area, and for each level of luminance, the mean RT was the median of 60 measurements.

\section{RESULTS}

At each of the three levels of luminance, the median SRTs decline when the area of the stimulus increases (an

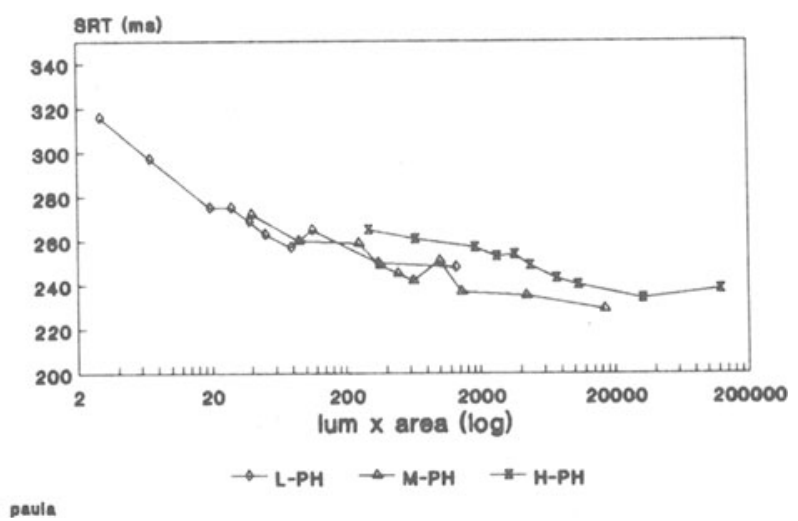

Figure 2. Individual simple reaction time (in milliseconds) as a function of area $\times$ luminance in Experiment 2. Area is expressed in pixels and luminance (in $\left.\mathbf{c d} / \mathrm{m}^{2}\right)$, as in Figure 1. 
Table 2

Exponents, Chronobasis $\left(t_{o}\right)$, and Confidence Coefficient for the Goodness of Fit When the Variable is Area $\times$ Intensity for Each Subject in the Two Experiments

\begin{tabular}{cccccccc}
\hline & \multicolumn{3}{c}{ Experiment 1} & & \multicolumn{3}{c}{ Experiment 2} \\
\cline { 2 - 4 } \cline { 6 - 8 } Subjects & Exponent & $t_{o}$ & $r^{2}$ & & Exponent & $t_{o}$ & $r^{2}$ \\
\hline N.R. & -0.1313 & 192 & .8935 & & -0.0771 & 173 & .6720 \\
P.H. & -0.2866 & 208 & .8088 & & -0.0841 & 185 & .7767 \\
\hline
\end{tabular}

example is shown in Figure 1). The equation of Piéron's law was fitted to individual data separately for the three luminance conditions in Experiments 1 and 2. An iterative least squares solution was applied to the logtransformed data in order to find the set of the three parameters $\left(t_{o}, \beta\right.$, and $\alpha$ in Equation 1), which maximizes the correlation coefficient (see Mansfield, 1973).

In every luminance condition of the two experiments, the equation of Piéron's law provided a good fit to the data. A summary of the parameter values is shown in Table 1 . In the two experiments, the exponent of the function decreases when the luminance increases.

In the second step of the analysis, we examined the relationship between SRTs and the product of the area by its luminance $(A \times I)$. The results of Experiment 2 are shown for each subject in Figure 2. In this figure, data obtained with the same luminance level are linked together.

A summary of the parameter values, when a single $\mathrm{Pi}$ éron's function is fitted to the results, is shown in Table 2. Compared to the former analysis, the exponents appear reduced, on average, when the variable is the product of area $\times$ luminance. The difference in exposure time does not generate systematic differences, either in the adjusted parameters or in the median or mean SRTs of Experiments 1 and 2 . Finally, the goodness of the fit appears lower for the data of Experiment 2.

Visual inspection of the figures reveals the origin of the decrease in goodness of fit. On every occasion, at least two points do not fit correctly with the function. They correspond to the two lowest areas of the lowest luminance level.

\section{DISCUSSION AND CONCLUSION}

The decline of SRTs with the increase in area (or size) is not likely to be explained as a result of a change in the fundamental spatial frequency of the stimuli. In effect, while the range of fundamental frequencies used here is comparable to the one used, for example, in Breitmeyer (1984) (0.5-10 cpd), the range of changes in the SRTs is much smaller in our conditions than in his conditions. A more definite answer requires further experiments. However, even if fundamental spatial frequencies can account partly for the decline, other factors must have a much larger influence, as revealed by the nearly unique function obtained in combining area and luminance (see Figure 2).

The second factor to be examined is the total flux. If total flux were the determinant here, one would expect shorter reaction times in Experiment 1 than in Experiment 2 since more light quanta reach the retina in the first case. In fact, no difference is observed. This result suggests that flux is not the essential determinant of the result.

Now, probability summation remains the most likely assumption. Increasing area and luminance increase the global neuronal activity in the visual system. SRTs would then depend on that global activity more than on the local activity related to luminance itself. Our results suggest that probability summation combines with spatial summation, es- pecially in the case of small stimuli presented for a short time ( $32 \mathrm{msec})$. There is, in fact, energy summation when the area is smaller than the mean size of the receptive field. This happens at the lowest level of luminance for the two lowest sizes, which are precisely lower than the limit of the Ricco's area in our experimental conditions.

In conclusion, the most likely explanation of the present results invokes two main factors. First, as expected from Piéron's law, SRTs decline when the luminance of the stimulus increases. Second, for a constant luminance level, and beyond the limits of areal summation, an increase in the area of the stimulus decreases SRTs because of a probability summation effect (e.g., Link, 1992). In other words, area per se is not the determinant of the SRT.

\section{REFERENCES}

BoNNET, C. (1990). How to bridge the gap between magnitude estimation and reaction time. In F. Müller (Ed.), Fechner day 90 (pp. 3742). Würzburg: International Society for Psychophysics.

BREITMEYER, G. B. (1984). Visual masking: An integrative approach. New York: Oxford University Press.

Colonius, H. (1990). Possibly dependent probability summation of reaction time. Journal of Mathematical Psychology, 34, 253-275.

Grice, G. R. (1968). Stimulus intensity and response evocation. Psychological Review, 75, 359-373.

Grice, G. R., Nullmeyer, R., \& Schnizlein, J. M. (1979). Variable criterion analysis of brightness effects in simple reaction time. Journal of Experimental Psychology: Human Perception \& Performance, 5, 303-314.

Hood, D. C., \& Finkelstein, M. A. (1986). Sensitivity to light. In K. R. Boff, L. Kaufman, \& J. P. Thomas (Eds.), Handbook of perception and human performance (Vol. 1, pp. 5.1-5.66). New York: Wiley.

Link, S. W. (1992). The wave theory of difference and similarity. Hillsdale, NJ: Erlbaum.

LUCE, R. D. (1986). Response time. New York: Oxford University Press.

LUCE, R. D., \& GREEN, D. M. (1972). A neural timing theory for response times and the psychophysics of intensity. Psychological Review, 79, 14-57.

MANSFIELD, R. J. W. (1973). Latency functions in human vision. $\mathrm{Vi}$ sion Research, 13, 2219-2234.

McGilL, W. J. (1967). Neural counting mechanisms and energy detection in audition. Journal of Mathematical Psychology, 4, 351-376.

NoRWICH, K. H. (1977). On the information received by sensory receptors. Bulletin of Mathematical Biology, 39, 453-461.

NoRwICH, K. H. (1984). The psychophysics of taste from the entropy of the stimulus. Perception \& Psychophysics, 35, 269-278.

Norwich, K. H., SeburN, C. N. L., \& Axelrad, E. (1989). An information approach to reaction times. Bulletin of Mathematical Biology, 51, 347-358.

Parker, D., \&alzen, E. A. (1977). Latency changes in the human visual evoked response to sinusoidal gratings. Vision Research, 17, 1201-1204.

Pí́Ron, H. (1920). Nouvelles recherches sur l'analyse du temps de latence sensorielle en fonction des intensités excitatrices. L'Année Psychologique, 22, 58-142.

Pif́ron, H. (1952). The sensations. New Haven: Yale University Press.

RESTLE, F. (1961). The psychology of judgment and choice: A theoretical essay. New York: Wiley.

TEICHNER, W. H., \& KREBS, M. J. (1972). Laws of simple visual reaction time. Psychological Review, 79, 344-358.

TolnURST, D. J. (1975). Reaction times in the detection of gratings by human observers: A probabilistic mechanism. Vision Research, 15, 1151-1155.

UENO, T. (1976). Luminance-duration relation in reaction time to spectral stimuli. Vision Research, 16, 721-725.

\section{NOTE}

1. The term intensity will be taken here in its broad meaning, since the aim of the paper is precisely to find out what is the intensive determinant of the SRT.

(Manuscript received April 24, 1992.) 